\title{
Indicators for secondary carcinoma in head and neck cancer patients following curative therapy: A retrospective clinical study
}

\author{
BEATRICE KUHLIN, BENEDIKT KRAMER, VYTIS NEFAS, NICOLE ROTTER and CHRISTOPH ADERHOLD
}

Department of Otorhinolaryngology-Head and Neck Surgery, University Hospital Mannheim, D-68167 Mannheim, Germany

Received December 19, 2018; Accepted November 21, 2019

DOI: $10.3892 / \mathrm{mco} .2020 .2004$

\begin{abstract}
Patients with head and neck squamous cell carcinoma (HNSCC) are at risk for local and regional relapse, as well as for occurrence of synchronous or metachronous secondary carcinoma. The aim of this retrospective study was to evaluate the frequency of secondary malignancies amongst HNSCC patients and their association with age, sex and TNM classification, as well as smoking and alcohol abuse. Data from 394 patients with HNSCC who were treated at the Department of Otorhinolaryngology-Head and Neck Surgery of the University Hospital Mannheim between 2011 and 2015 were retrieved and analyzed using t-tests and $\mathrm{P} \leq 0.05$ was considered statistically significant. Of the 394 patients, $50(12.7 \%)$ developed a secondary carcinoma. In this cohort, $>70 \%$ of secondary malignancies were diagnosed using clinical inspection or microlaryngoscopy. The majority of secondary malignancies were identified in the oropharynx, with men being more often affected overall. Continued abuse of carcinogenic substances appeared to increase the incidence of secondary carcinoma, whereas the localization of the primary tumor, age, sex or TNM classification were not identified as significant indicators of the occurrence of a secondary carcinoma. The purpose of the present study was to emphasize the importance of intensive follow-up to ensure early detection of secondary malignancies. The aim was to help predict numbers and occurrence within smaller cohorts, and to evaluate the quality of data collected during the establishment of a certified tumor center. To fully evaluate the role of continued exposure to noxious substances and other possible contributing factors, and in order to improve the rate of early diagnosis and establish preventive strategies, multicentered studies with larger cohorts are required.
\end{abstract}

Correspondence to: $\mathrm{Dr}$ Beatrice Kuhlin, Department of Otorhinolaryngology-Head and Neck Surgery, University Hospital Mannheim, 1-3 Theodor-Kutzer-Ufer, D-68167 Mannheim, Germany E-mail: beatrice.kuhlin@umm.de

Key words: secondary carcinoma, metachronous, synchronous, head and neck squamous cell carcinoma

\section{Introduction}

Head and neck cancer affects $\sim 686,000$ new patients annually, 375,000 of whom eventually succumb to the disease according to the latest data from the World Health Organization (1). These data indicate that head and neck squamous cell carcinoma (HNSCC) is the sixth most common type of cancer worldwide. Thus, a growing number of patients diagnosed with head and neck cancer are confronted with not only the risk of local and regional relapse following curative therapy, but also the occurrence of a synchronous or metachronous secondary carcinoma. According to GLOBOCAN, the incidence of secondary carcinoma in different localizations in the head and neck is as follows: Oral cavity 4.3, larynx 2.2, pharynx 2.0, and nasopharynx 1.2 per $100,000(2,3)$. Mortality depends on the localization of the primary tumor and the stage of the disease. Globally, a total of $4.58 \%$ of all cancer patients succumb to head and neck carcinoma (2).

Multiple primary malignancies is a term used to describe the occurrence of two or more malignancies at different anatomical localizations. These are defined as synchronous malignancies if the secondary carcinoma is diagnosed within 6 months of the primary carcinoma, or as metachronous if it is diagnosed $>6$ months after the primary carcinoma (4). In a retrospective study of 6,545 oncological patients in China, a secondary malignancy was identified in 72 cases $(1.1 \%)$. In the present study, the highest incidence of secondary malignancies was noted among patients with head and neck cancer, followed by colorectal carcinoma and lung tumors (5). A retrospective study from India analyzed the data of 23,260 patients and found that 41 patients $(0.18 \%)$ had developed a secondary carcinoma; these secondary malignancies were most common among patients with head and neck cancer, followed by gynecological tumors (6). An analysis from the USA, including 2,116,163 patients, identified 170,865 (8.1\%) cases with a secondary carcinoma; in that study, the most common localizations of a secondary malignancy were the lung (18\%), colon $(12 \%)$, prostate $(9 \%)$, and bladder (8\%) (7). These differences confirm a wide variation in different parts of the world.Precise epidemiological data regarding the incidence and distribution of synchronous and metachronous malignancies are lacking, and the incidence in the current literature varies between 1.8 and $34.6 \%$ (8-19). A study from the Department of Health and Human Services in USA analyzed 58,363 patients with head and neck cancer between 1973 and 2008, and 
revealed that $11.7 \%(n=6,855)$ of the patients developed a secondary tumor. Patients with laryngeal carcinoma had the highest incidence of secondary tumors outside the head and neck area (13.6\%), whereas patients with primary oral cancer had the highest incidence of secondary malignancies within the head and neck area [oral cavity (58.4\%), larynx (18.2\%) and oropharynx (13.3\%)] (8). Metachronous carcinomas developed more often compared with synchronous carcinomas and, according to the literature, their frequency varied between 4.7 and 24\%, whilst synchronous tumors were found in $0.3-14 \%$ of the patients $(9,11,13,15,20)$. Di Martino et al categorized secondary tumors based on the time of diagnosis. Their retrospective study investigated 1,803 patients with primary tumors in the head and neck area, among whom $34(1.9 \%)$ were found to have a synchronous carcinoma and $86(4.8 \%)$ developed a metachronous carcinoma. Of those 86 patients, 50 developed the metachronous tumor within 5 years after primary tumor diagnosis, 22 patients developed the metachronous tumor within 6-10 years, and 14 patients after $>10$ years. Whether metachronous carcinomas with such long latency should be classified as secondary malignancies, with an etiological and pathogenic connection to the primary carcinoma, or as independent primary tumors, warrants further discussion (13).

The most important risk factors for HNSCC are alcohol and nicotine abuse, the chewing of betel nuts, insufficient dental hygiene, and infection with human papillomavirus, particularly the high-risk subtypes 16 and 18 (21-26). Smoking and drinking are major contributors to field cancerization and the occurrence of secondary malignancies (27-29). According to Ruback et al the combination of alcohol and tobacco abuse increases the risk of SCC up to 40-fold compared with either alcohol or tobacco alone. It may be inferred that alcohol serves as a dissolvent for some tobacco carcinogens and facilitates cellular uptake (30). A study by Pezzuto et al investigated the combined use of alcohol and tobacco in 11,221 patients with head and neck cancer; $72 \%$ of the patients claimed to have consumed tobacco or alcohol regularly; $4 \%$ of those patients claimed to have consumed alcohol alone, $33 \%$ tobacco alone, and $35 \%$ reported consuming both regularly (31). Both carcinogenic substances have a dose-effect relationship and cause cumulative toxicity. Carcinogenic effects may appear for even up to 10 years after the cessation of drinking and smoking (27). Smokeless forms of tobacco, such as snuffed or chewed tobacco, sometimes combined with betel quid or other preparations, such as the areca nut, are particularly consumed in India, North and South America and northern Europe. Betel nuts contain several alkaloids (guvacin, arecaidin, guvacoline and arecoline) that are addictive and have carcinogenic properties; they also inhibit tumor suppressor genes and DNA-repair mechanisms, causing uncontrolled cell proliferation within the mucosa and, thus, increasing the risk of cancer of the oral cavity and esophagus (28,32-35).

The development of secondary malignancies in the head and neck area may be explained by field cancerization. This term was coined in 1953 by Jaiswal et al, who observed multiple areas of SCC within the oropharyngeal cavity of a patient. Field cancerization describes the occurrence of multiple sites with invasive growth and areas of dysplasia within the mucosa. Despite the metacentric origin, field cancerization appears to be an important factor for the occurrence of secondary SCCs after therapy completion (21).

Secondary malignancies occur frequently in patients with head and neck carcinoma and may seriously affect the prognosis of the patients, which warrants a close follow-up; therefore, we herein sought to evaluate the frequency of secondary malignancies among head and neck cancer patients in our center and identify possible clinical indicators of their occurrence following curative tumor therapy. The aim of the present study was to help predict the occurrence of secondary cancer within smaller cohorts of other certified tumor centers.

\section{Patients and methods}

Ethics statement. The present study was conducted in full accordance with the Declaration of Helsinki and was approved by the Ethics Committee II of the Medical Faculty of Mannheim at the University of Heidelberg, Mannheim, Germany (file no. 2016-827R-MA).

Patients. A total of 380 patients with HNSCC who were treated at University Hospital Mannheim between 2006 and 2015 were enrolled. Patients for whom no complete follow-up data could be obtained, or those who died during the follow-up period, were excluded. Patients with secondary carcinomas other than SCC, i.e., sarcomas, lymphomas, etc., as well as patients receiving palliative treatment were also excluded. All included patients underwent a thorough clinical inspection, including a physical and endoscopic examination of the head and neck area, as well as sonographic and radiological imaging for staging of the disease. Bronchoscopy, gastroscopy, pharyngoscopy and microlaryngoscopy were part of staging for all patients in order to identify secondary malignancies, as well as regional and distant metastases. After staging, patients received therapy according to the primary tumor stage. Multimodal therapy included tumor resection, neck dissection, adjuvant chemoradiotherapy, or definitive chemoradiotherapy when surgical therapy was refused or deemed not suitable. All patients underwent regular follow-ups at the clinic, including head and neck examination, ultrasonography of the neck, microlaryngoscopy, esophagogastroscopy and bronchoscopy, with a mean interval of 4.8 months (standard deviation, 1.8 months). Patient data were retrieved from the internal tumor database of our institution, patient files, medical reports, surgical reports, and interdisciplinary tumor board protocols. Information was also obtained on patient sex, age, TNM stage, date of diagnosis, localization of the primary tumor, secondary carcinomas and their localization (synchronous and metachronous), and tobacco and alcohol consumption. The initial hypothesis was that no more than $20 \%$ of all cases would be positive for a secondary carcinoma. Another goal of the present study was to investigate possible clinical indicators for the occurrence of secondary carcinomas.

Statistical analysis. Statistical analysis was performed with JMP 11 software (SAS Institute, Inc.). A t-test was performed for independent variables. $\mathrm{P} \leq 0.05$ was considered to indicate statistically significant differences. 


\section{Results}

Patient characteristics. The majority of the 380 patients were male $(n=269 ; 70.8 \%)$. The mean age was 63.5 years, with a standard deviation of 10.9 years (range, 24-94 years). The majority of the patients were diagnosed with laryngeal carcinoma $(n=133 ; 35 \%)$, followed by $128(33.7 \%)$ patients with oropharyngeal cancer. A total of 67 patients (17.6\%) had carcinoma of the oral cavity. The distribution of tumor localization is shown in Table I.

The 7th edition of TNM classification was applied for cancer staging (36). The most common T stage was T2 (32.6\%), followed by $\mathrm{T} 1(29.5 \%)$. The most common nodal status was N0 $(46.8 \%)$, followed by N2 $(41.1 \%)$. The majority of the patients had no distant metastases (M0; 91.8\%). The distribution of TNM stage of the primary tumors is shown in Table II.

Localization of secondary carcinomas. Between 2011 and 2015, a total of 39 patients $(10.3 \%)$ developed a secondary carcinoma. Secondary carcinomas exhibited a similar distribution pattern to that of the primary tumors. The most common localizations of the secondary malignancies were the oropharynx (41\%), larynx (25.6\%) and oral cavity $(20.6 \%)$. The localizations of the secondary carcinomas diagnosed in the patients of the present study are summarized in Table III.

Synchronous and metachronous secondary cancers. Secondary malignancies were differentiated into synchronous and metachronous. The time of diagnosis of the secondary carcinoma was used to distinguish between the two patient cohorts. A total of $22(5.8 \%)$ of the patients developed a synchronous tumor (diagnosed within the first 6 months after the primary tumor), whilst 17 patients (4.5\%) developed a metachronous tumor (occurring between 6 months and 5 years after the primary tumor). Figure 1 displays the number of diagnosed secondary malignancies (synchronous and metachronous) within the collective between 2006 and 2015 . Whilst there was an increase in diagnosed secondary malignancies from 2006 to 2012, the number reached a steady state between 2012 and 2013 and decreased between 2014 and 2015.

Associations between clinicopathological characteristics and secondary cancer development. A Chi-square test and a Fisher's exact test were performed to analyze the associations between different primary tumor localizations and the development of secondary carcinomas. A P-value of 0.1 confirmed There was no significant association between the localization of the primary tumor and the development of a secondary carcinoma $(\mathrm{P}=0.1)$, although the majority of secondary carcinomas affected patients with primary oropharyngeal $(n=16$; $4.2 \%$ of all patients; $41 \%$ of all secondary carcinomas) and laryngeal carcinomas $(n=13 ; 3.4 \%$ of all patients; $25.6 \%$ of all secondary carcinomas).

Whether patient sex was a relevant factor for the occurrence of secondary carcinomas was investigated. No significant correlation between sex and secondary malignancies was observed $(\mathrm{P}=0.51)$, although more men $(31 ; 8.2 \%$ of all patients) rather than women $(8 ; 2.1 \%$ of all patients) developed a secondary carcinoma. The distribution of secondary malignancies amongst men and women is summarized in Table IV.
Table I. Distribution of primary tumor localization.

\begin{tabular}{lcc}
\hline Localization & Frequency & $\%$ \\
\hline Larynx & 133 & 35 \\
Oropharynx & 128 & 33.7 \\
Oral cavity & 67 & 17.6 \\
Hypopharynx & 52 & 13.7 \\
Total & 380 & 100.0 \\
\hline
\end{tabular}

Table II. Distribution of TNM stage of primary tumors within the cohort.

\begin{tabular}{lcc}
\hline A, T stage & & \\
\hline Stage & Frequency & $\%$ \\
\hline Carcinoma in situ & 7 & 1.8 \\
T1 & 112 & 29.5 \\
T2 & 124 & 32.6 \\
T3 & 76 & 20 \\
T4 & 61 & 16.1 \\
Total & 380 & 100.0 \\
\hline
\end{tabular}

$\mathrm{B}, \mathrm{N}$ stage

\begin{tabular}{lcc}
\hline Stage & Frequency & $\%$ \\
\hline N0 & 178 & 46.8 \\
N1 & 32 & 8.4 \\
N2 & 156 & 41.1 \\
N3 & 10 & 2.6 \\
Nx & 4 & 1.1 \\
Total & 380 & 100.0 \\
\hline
\end{tabular}

C, M stage

\begin{tabular}{lcc}
\hline Stage & Frequency & $\%$ \\
\hline M0 & 349 & 91.8 \\
M1 & 12 & 3.2 \\
Mx & 19 & 5 \\
Total & 380 & 100.0
\end{tabular}

The youngest patient in our study population with a secondary carcinoma was 50 years old, while the oldest was 87 years old. A t-test was performed in order to evaluate patient age as a possible risk factor for the development of secondary carcinomas. A P-value of 0.27 (95\% CI: $-1.07,3.7)$ could not prove this hypothesis, which suggests that the development of secondary malignancies is not significantly associated with patient age.

A total of $42 \%$ of all secondary carcinomas had a T1 primary tumor and $26 \%$ had a $\mathrm{T} 2$ primary tumor $(\mathrm{P}=0.39)$. 
Table III. Distribution of secondary carcinoma localization.

\begin{tabular}{lcc}
\hline Localization & Frequency & $\%$ \\
\hline Oropharynx & 16 & 41 \\
Larynx & 10 & 25.6 \\
Oral cavity & 8 & 20.6 \\
Hypopharynx & 5 & 12.8 \\
Total & 39 & 100.0 \\
\hline
\end{tabular}

Table IV. Distribution of secondary carcinoma amongst male and female patients.

\begin{tabular}{lccc}
\hline $\begin{array}{l}\text { Secondary } \\
\text { carcinoma }\end{array}$ & Male & Female & Total \\
\hline No, n (\%) & $269(70.8)$ & $72(18.9)$ & $341(89.7)$ \\
Yes, n (\%) & $31(8.2)$ & $8(2.1)$ & $39(10.3)$ \\
Total & $300(78.9)$ & $80(21.1)$ & $380(100.0)$ \\
\hline
\end{tabular}

A total of $48 \%$ of the patients had a lymph node status of N0, and another $48 \%$ had $\mathrm{N} 2 \mathrm{a}, \mathrm{b}$ or c disease $(\mathrm{P}=0.39)$. Of all secondary tumors, $98 \%$ had no distant metastasis at the time of diagnosis $(\mathrm{P}=0.22)$. Chi-squared tests proved that the TNM status of the primary tumors did not represent a risk factor for the development of a secondary carcinoma.

A total of 138 patients reported regular consumption of carcinogenic substances, such as tobacco products, or alcoholic beverages; a total of $17.4 \%$ (70 patients) reported tobacco use alone, 5.1\% (20 patients) reported alcohol use alone, and $12.2 \%$ (48 patients) reported use of both alcohol and tobacco. Two of the patients $(0.5 \%)$ reported other forms of drug consumption. No information regarding the consumption of carcinogenic substances was available for the remaining 242 patients. A Chi-square test was performed to evaluate the association between consumption of carcinogenic substances and the development of secondary malignancies. Due to incomplete data regarding the substance abuse profile of 242 patients, no reliable general conclusion can be drawn from this statistical analysis. Although no significant association could be confirmed $(\mathrm{P}=0.89)$, a larger cohort with greater data availability should be investigated. A summary of the aforementioned statistical results is presented in Table V.

\section{Discussion}

The present study was designed to investigate indicators for secondary carcinomas in patients with head and neck cancer. The data of 380 patients with head and neck cancer were assessed to retrospectively analyze the incidence and frequency of synchronous and metachronous secondary carcinomas.

Patients with head and neck cancer are prone to develop multiple primary tumors $(5,6)$. A possible explanation for this phenomenon is the concept of field cancerization, coined by Jaiswal et al in 1953 (21). The reported incidence of secondary malignancies ranges between 1.8 and $34.6 \%$ (8-19). We were
Table V. Association between the development of secondary carcinoma and different cofactors.

\begin{tabular}{lc}
\hline Cofactors & P-value \\
\hline Primary tumor location & 0.1 \\
Sex & 0.51 \\
Age & 0.27 \\
T stage of primary tumor & 0.39 \\
N stage of primary tumor & 0.39 \\
M stage of primary tumor & 0.22 \\
Continued exposure to carcinogenic substances & 0.89 \\
\hline
\end{tabular}

able to confirm our hypothesis that secondary head and neck malignancies occur in $<20 \%$ of the patients in the present study. Of the 380 patients, 39 developed a secondary malignancy $(10.3 \%)$. Increasing numbers of secondary carcinomas were detected between $2006(n=1)$ and $2012(n=13)$. After 2012 , the number of secondary carcinomas stabilized and then declined again in 2014. During this period, our hospital established a certified head and neck cancer center, which may explain the growing number of diagnosed secondary carcinomas due to structured follow-ups, followed by a decline as a result of multi-disciplinary therapy. Furthermore, the establishment of withdrawal programs may have had a positive impact on the incidence of secondary malignancies (37-39). The pattern of anatomical distribution for secondary carcinomas was similar to that for primary tumors. The most common localization was the oropharynx (32\%) followed by the larynx $(20 \%)$ and oral cavity $(16 \%)$. The most common localization of secondary malignancies varies in the current literature, and includes the lung, larynx and oropharynx $(2,13,11)$. However, different follow-up standards were used. In the present study, all patients underwent a chest $\mathrm{X}$-ray and a full endoscopic evaluation. Wax et al compared a computed tomography (CT) scan of the chest with simple $\mathrm{X}$-ray and bronchoscopy. The CT scan exhibited the highest sensitivity at $87 \%$ (40). Another study reported that early-stage secondary malignancies can barely be detected on CT scans, so this examination should only be used in advanced-stage secondary carcinomas (stage III and IV) (41). Bronchoscopy is an invasive procedure, yet it allows biopsies and is associated with no exposure to radiation (14). In our cohort, only a small number $(n=2 ; 5 \%)$ of secondary carcinomas were successfully diagnosed by bronchoscopy. According to current evidence, metachronous carcinomas are found more often compared with synchronous carcinomas (20). Depending on the study, the incidence varies between 4.7 and $24 \%$ for metachronous tumors, whereas synchronous secondary carcinomas are reported in $0.3-14 \%$ of the patients $(9,11,13,15,20)$. In the present study, $6.2 \%$ of the cohort were found to have a synchronous tumor and $4.1 \%$ were found to have a metachronous tumor. The long interval of 6 months and 5 years leaves room for detection bias. Not all patients comply to the full scale of the follow-up program, whereas some patients relocate and cannot be evaluated to the full extent. Although the cohort of the present study cannot match a multicentered international 


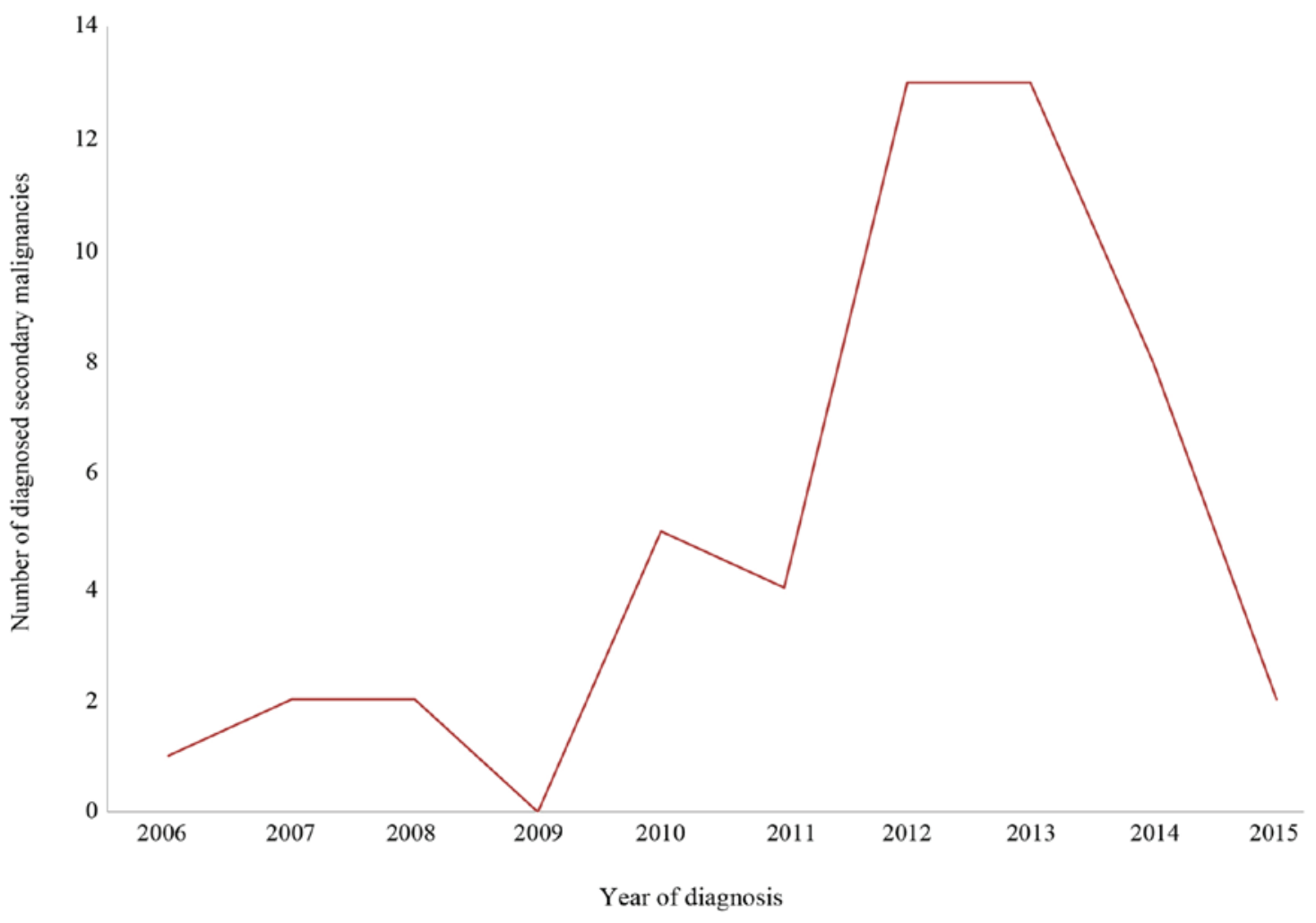

Figure 1. Number of diagnosed secondary malignancies annually.

cohort, the aim of this study was to evaluate the occurrence of secondary carcinomas within the confined environment of a single treatment center and, thus, help predict numbers and occurrences within smaller cohorts. The present study further aimed to evaluate the quality of data collected during the establishment of a certified tumor center.

As regards demographic patient characteristics, the mean age of the cohort was 64 years, and $78.9 \%$ of the patients were men, which is consistent with other studies $(8,42)$. Malignancies in the head and neck area were more common among patients aged 60-70 years and significantly more frequent in men $(\mathrm{n}=31 ; 79.5 \%$ of all secondary carcinomas) rather than women ( $n=8 ; 20.5 \%$ of all secondary carcinomas). A t-test revealed that the association between age and secondary malignancy development in our study was not statistically significant $(\mathrm{P}=0.27,95 \%$ CI: $-1.08,3.74)$. The sex predilection may be explained by the higher consumption of noxious substances by men. Similar studies report men to be more prone to the development of secondary malignancies $(11,20)$. The majority of patients in our cohort were diagnosed with a primary $\mathrm{T} 2$ (31.98\%) or T1 tumor (28.93\%), which confirms the findings reported by Ruback et al (30). A similar distribution of nodal and metastatic status was found in a cohort formed by the University of Tokyo (9). Patients are more likely to recognize lesions and abnormalities in the upper airway at an early stage. However, non-specific symptoms, such as hoarseness, which may be initially attributed to a common cold, may delay primary diagnosis. Regardless, $60 \%$ of all laryngeal malignancies are diagnosed at an earlier stage compared with subglottic or supraglottic malignancies (28). Tumors of the oral cavity may also be detected at an early stage. Of the 112 cases, $88.4 \%$ had a tumor size of T1 or T2 (12). A retrospective study of 52 patients with secondary carcinomas in the head and neck area conducted by Saito et al also found the index tumor size to be $\mathrm{T} 1$ or $\mathrm{T} 2$ in $62 \%$ of the cases (9). However, TNM classification was not found to be a significant indicator for the occurrence of secondary carcinomas in the present study.

A secondary tumor most often developed among patients with primary oropharyngeal carcinoma (16 cases; $4.2 \%$ of all patients; $41 \%$ of all secondary carcinomas), although oropharyngeal tumors were not the most common primary tumors. Patients with laryngeal cancer ranked second regarding the occurrence of secondary carcinomas (13 cases; $3.4 \%$ of all patients; $33 \%$ of secondary carcinomas). The lowest incidence of secondary carcinomas was observed for primary oral cavity and hypopharyngeal cancers (Table III). Dequanter et al reported the larynx, hypopharynx and oropharynx (in descending order) as the most common sites of secondary carcinoma development (43); Patrucco et al confirmed these results (11). In a large study with 58,363 carcinomas of the head and neck area, the majority of secondary carcinomas were diagnosed in patients with a primary carcinoma of the oral cavity (967 cases), larynx (353 cases), oropharynx (281 cases) and hypopharynx (76 cases) (8). Thus, there is an inconsistency in the current literature regarding the association between the localization of the primary tumor and secondary carcinomas $(44,45)$. We were unable to identify a significant association between the localization of the primary carcinoma and the development of secondary carcinomas in the present study $(\mathrm{P}=0.09)$.

The combined abuse of tobacco and alcohol increases the risk of SCC (30). A retrospective study by Ruback et al reported 
consumption of tobacco and alcohol by 1,351 patients with malignancies in the head and neck area. A total of 747 patients $(75.15 \%)$ reported regularly consuming tobacco, $579(58.25 \%)$ alcohol, and 547 (54\%) both (30). Another publication by Leon et al categorized $88.9 \%$ as smokers and $87.7 \%$ as regular alcohol consumers $(n=4,298)(44)$. In the present study, 142 of the 380 patients reported regular alcohol and/or tobacco consumption. Tobacco use was more frequent $(18.27 \%$ of patients), whereas 48 patients $(12.18 \%)$ reported regular use of both alcohol and tobacco. In comparison to the available evidence, the number of patients consuming noxious substances in our data is low and was only obtained from 142 patients due to insufficient patient history, or patients not admitting to substance abuse. However, our results support the fact that nicotine and alcohol have carcinogenic properties. A total of $18.3 \%$ of patients without and $18 \%$ with secondary carcinomas were regular smokers. Regular smokers and drinkers developed secondary carcinomas more often compared with those who did not consume both substances regularly. Our data were not sufficient to establish a statistically significant effect of smoking and drinking on the development of secondary carcinomas. A study from the Head and Neck Center in St. Pau investigated 3,631 patients and confirmed that continued smoking and/or alcohol consumption after primary therapy significantly increased the risk for secondary tumors $(\mathrm{P}<0.001)(45)$. It is a matter for discussion whether invasive or mutilating procedures, such as laryngectomy, may trigger changes in drinking or smoking habits, since the majority of our patients with secondary carcinomas had $\mathrm{T} 1$ or T2 primary tumors. Eichler et al investigated 359 patients after laryngectomy; $68.5 \%$ of the patients quit smoking completely, $10.6 \%$ continued smoking, $6.1 \%$ had not been smokers before, whereas no data could be obtained for $14.8 \%$ of the cases. Regarding alcohol consumption, $28.1 \%$ of the patients continued alcohol consumption, whilst $70.5 \%$ tried to reduce consumption (42). Alcohol appears to have a higher addictive factor than nicotine; however, a more aggressive surgical approach does not appear to significantly affect the patient's behavior for either noxious substance.

Infection with high-risk types of human papillomavirus (HPV) is a well-known risk factor for the development of multiple carcinomas $(8-10,30)$. In the present cohort, no data could be acquired regarding the HPV status or cumulative dose of radiation for the primary tumors. However, several studies suggest that infection with high-risk HPV types 16 and 18 increases the risk of development of secondary carcinomas. A study by Li et al from 2018 stated that HPV-infected patients are generally immunosuppressed and, thus, may be predisposed to the development of secondary cancers (46). However, a current meta-analysis by Götz et al, investigating the diagnosis of HPV infection, reported a widely varying number of infections with HPV amongst cohorts, and concluded that previously published studies regarding this subject should be read critically and may not represent a basis for therapeutic decisions (47). Further immunosuppression in patients with HNSCC occurs during chemoradiation (48). Al-Taei et al observed an overall decreased T-cell response and accumulation of immunosuppressive effects in oropharyngeal cancer patients following chemoradiation (49). As regards chemoradiation alone, a study by Berrington de
Gonzalez et al demonstrated a significantly increased risk of developing secondary carcinomas in patients who received a radiation dose of $>5$ Gy (50). Since HNSCC patients regularly receive radiation with a cumulative dose of 40-60 Gy, these findings should be investigated further. Overall, the combination of virus- and treatment-induced immunosuppression may increase the risk of multiple carcinomas (51).

The primary limitation of this study was its retrospective design. The data on the consumption and abuse of noxious substances was particularly inconsistent and, thus, must be interpreted with caution. Another issue was recall bias: Treatment histories, medications and use of noxious substances, could not be fully recalled by the patients and physicians. When comparing the cohort of the present study to those of similar studies, it was found to be a representative sample. However, increasing the cohort size may help achieve statistically significant results in the case of smaller differences between groups. Further studies should collect data over a longer period of time, producing more consistent and detailed information.In conclusion, the study cohort is comparable to those of other studies, and appears to be a representative sample of head and neck cancer patients. The incidence of secondary carcinoma in this study was $10.3 \%$. The localization pattern of secondary carcinomas was similar to that of primary tumor sites. The majority of secondary carcinomas were found in the oropharynx (32\%), followed by the larynx (20\%) and the oral cavity (16\%). These results are in line with the concept of field cancerization, suggesting that secondary carcinomas may develop near the primary tumor site. However, the results of the present study were not statistically significant. Synchronous tumors occurred slightly more often compared with metachronous tumors (6.2 vs. $4.1 \%$, respectively). Age and sex did not significantly affect the occurrence or development of secondary carcinomas. Furthermore, no significant association was identified between the TNM status of the primary cancer and that of the secondary carcinoma. Regarding the consumption of noxious substances, a clear trend was observed in that persistent consumption of alcohol and tobacco after the primary diagnosis promoted the development of secondary carcinomas. Yet, due to the inconsistencies in the data collected from 252 patients in the cohort, the statistical significance of this association was not proven $(\mathrm{P}=0.89)$. Overall, avoiding the continued exposure to noxious substances, as well as early diagnosis and consistent treatment in a certified head and neck cancer center, appear to be key factors for decreasing the incidence of secondary carcinomas. Furthermore, the role of infection with high-risk HPV types, as well as the impact of chemoradiation, should be investigated further, as they appear to play a key role in the development of secondary malignancies.

\section{Acknowledgements}

The authors would like to thank Mrs. Sylvia Büttner, of the Institute for Medical Statistics, Biomathematics and Information Processing in Mannheim, for creating the statistical breakdown.

\section{Funding}

No funding was received. 


\section{Availability of data and materials}

Data were obtained from the oncological database for head and neck cancer at the ENT Tumor Center Mannheim.

\section{Authors' contributions}

VN analyzed and interpreted the data retrieved from the oncological database and was a major contributor to literature research. $\mathrm{BKu}$ interpreted the data and wrote the manuscript. BKr, NR and CA were major contributors in correcting and proofreading the final manuscript. CA and NR helped with acquiring the data. Further, NR and CA have given final approval of the version to be published. All authors read and approved the final manuscript.

\section{Ethics approval and consent to participate}

The study protocol was approved by the Ethics Committee II of the Medical Faculty of Mannheim at the University of Heidelberg, Mannheim, Germany (file no. 2016-827R-MA).

\section{Patient consent for publication}

Not applicable.

\section{Competing interests}

All the authors declare that they have no competing interests.

\section{References}

1. Ferlay J, Soerjomataram I, Dikshit R, Eser S, Mathers C, Rebelo M, Parkin DM, Forman D and Bray F: Cancer incidence and mortality worldwide: Sources, methods and major patterns in GLOBOCAN 2012. Int J Cancer 136: E359-E386, 2015.

2. International Agency for Research on Cancer (IARC): Cancer GLOBOCAN 2012: Cancer Tomorrow. http://globocan.iarc.fr/ Pages/summary table_pop_sel.aspx.

3. Larizadeh MH, Damghani MA and Shabani M: Epidemiological characteristics of head and neck cancers in southeast of iran. Iran J Cancer Prev 7: 80-86, 2014.

4. Xu LL and Gu KS: Clinical retrospective analysis of cases with multiple primary malignant neoplasms. Genet Mol Res 13: 9271-9284, 2014.

5. Jiao F, Yao LJ, Zhou J, Hu H and Wang LW: Clinical features of multiple primary malignancies: A retrospective analysis of 72 Chinese patients. Asian Pac J Cancer Prev 15: 331-334, 2014.

6. Bagri PK, Singh D, Singhal MK, Singh G, Mathur G, Jakhar SL, Beniwal S, Sharma N, Kumar HS, Sharma A and Bardia MR Double primary malignancies: A clinical and pathological analysis report from a regional cancer institute in India. Iran J Cancer Prev 7: 66-72, 2014.

7. Donin N, Filson C, Drakaki A, Tan HJ, Castillo A, Kwan L, Litwin $\mathrm{M}$ and Chamie K: Risk of second primary malignancies among cancer survivors in the United States, 1992 through 2008. Cancer 122: 3075-3086, 2016.

8. Birkeland AC, Rosko AJ, Chinn SB, Prince ME, Sun GH and Spector ME: Prevalence and outcomes of head and neck versus non-head and neck second primary malignancies in head and neck squamous cell carcinoma: An analysis of the surveillance, epidemiology, and end results database. ORL J Otorhinolaryngol Relat Spec 78: 61-69, 2016.

9. Saito Y, Ebihara Y, Ushiku T, Omura G, Kobayashi K, Ando M, Sakamoto T, Fukayama M, Yamasoba T and Asakage T: Negative human papillomavirus status and excessive alcohol consumption are significant risk factors for second primary malignancies in Japanese patients with oropharyngeal carcinoma. Japan J Clin Oncol 44: 564-569, 2014
10. Rennemo E, Zätterström U, Evensen J and Boysen M: Reduced risk of head and neck second primary tumors after radiotherapy. Radiother Oncol 93: 559-562, 2009.

11. Patrucco MS and Aramendi MV: Prognostic impact of second primary tumors in head and neck cancer. Eur Arch Otorhinolaryngol 273: 1871-1877, 2016.

12. Koo K, Harris R, Wiesenfeld D and Iseli TA: A role for panendoscopy? Second primary tumour in early stage squamous cell carcinoma of the oral tongue. J Laryngol Otol 129 Suppl 1: S27-S31, 2015.

13. Di Martino E, Sellhaus B, Hausmann R, Minkenberg R, Lohmann M and Esthofen MW: Survival in second primary malignancies of patients with head and neck cancer. J Laryngol Otol 116: 831-838, 2002.

14. Kesting MR, Robitzky L, Al-Benna S, Steinstraesser L, Baurecht H, Wolff KD, Hölzle F, Nieberler M, Mücke T and Loeffelbein DJ: Bronchoscopy screening in primary oral squamous cell carcinoma: A 10 -year experience. Br J Oral Maxillofac Surg 47: 279-283, 2009.

15. Schwartz LH, Ozsahin M, Zhang GN, Touboul E, De Vataire F, Andolenko P, Lacau-Saint-Guily J, Laugier A and Schlienger M: Synchronous and metachronous head and neck carcinomas. Cancer 74: 1933-1938, 1994.

16. Friedrich RE: Primary and second primary cancer in 649 patients with malignancies of the maxillofacial region. Anticancer Res 27: 1805-1818, 2007.

17. Panosetti E, Luboinski B, Mamelle G and Richard JM: Multiple synchronous and metachronous cancers of the upper aerodigestive tract: A nine-year study. Laryngoscope 99: 1267-1273, 1989.

18. Haughey BH, Gates GA, Arfken CL and Harvey J: Meta-analysis of second malignant tumors in head and neck cancer: The case for an endoscopic screening protocol. Ann Otol Rhinol Laryngol 101: 105-112, 1992.

19. Chuang SC, Scelo G, Tonita JM, Tamaro S, Jonasson JG, Kliewer EV, Hemminki K, Weiderpass E, Pukkala E, Tracey E, et al: Risk of second primary cancer among patients with head and neck cancers: A pooled analysis of 13 cancer registries. Int J Cancer 123: 2390-2396, 2008.

20. Tiwana MS, Hay J, Wu J, Wong F, Cheung W and Olson RA: Incidence of second metachronous head and neck cancers: Population-based outcomes over 25 years. Laryngoscope 124: 2287-2291, 2014.

21. Jaiswal G, Jaiswal S, Kumar R and Sharma A: Field cancerization: Concept and clinical implications in head and neck squamous cell carcinoma. J Exp Ther Oncol 10: 209-214, 2013.

22. Angadi PV, Savitha JK, Rao SS and Sivaranjini Y: Oral field cancerization: Current evidence and future perspectives. Oral Maxillofac Surg 16: 171-180, 2012.

23. Fortuna $G$ and Mignogna MD: Oral field cancerization. CMAJ 183: 1622, 2011.

24. Kreimer AR, Clifford GM, Boyle P and Franceschi S: Human papillomavirus types in head and neck squamous cell carcinomas worldwide: A systematic review. Cancer Epidemiol Biomarkers Prev 14: 467-475, 2005.

25. Franceschi S, Muñoz N, Bosch XF, Snijders PJ and Walboomers JM: Human papillomavirus and cancers of the upper aerodigestive tract: A review of epidemiological and experimental evidence. Cancer Epidemiol Biomarkers Prev 5: 567-575, 1996.

26. Kaatsch P, Spix C, Katalinic A, Hentschel S, Luttman S, Stegmaier C, Caspritz S, Christ M, Ernst A, Folkerts J, et al: Cancer in Germany 2011/2012. Robert Koch-Institute (Hrsg) and the society of the epidemiological Cancer-registry in Germany eV (Hrsg) Berlin, 2015. 2015; 10th Issue. doi: 10.17886/rkipubl-2015-004.

27. Chi AC, Day TA and Neville BW: Oral cavity and oropharyngeal squamous cell carcinoma-an update. CA Cancer J Clin 65: 401-421, 2015.

28. Belcher R, Hayes K, Fedewa S and Chen AY: Current treatment of head and neck squamous cell cancer. J Surg Oncol 110: 551-574, 2014.

29. Steward BW and Wild CP (eds): World Cancer Report 2014. International Agency for Research on Cancer, Lyon, France. http://publications.iarc.fr/Non-Series-Publications/World-CancerReports/World-Cancer-Report-2014.

30. Ruback MJ, Galbiatti AL, Arantes LM, Marucci GH, Russo A, Ruiz-Cintra MT, Raposo LS, Maniglia JV, Pavarino ÉC and Goloni-Bertollo EM: Clinical and epidemiological characteristics of patients in the head and neck surgery department of a university hospital. Sao Paulo Med J 130: 307-313, 2012. 
31. Pezzuto F, Buonaguro L, Caponigro F, Ionna F, Starita N, Annunziata C, Buonaguro FM and Tornesello ML: Update on head and neck cancer: Current knowledge on epidemiology, risk factors, molecular features and novel therapies. Oncology 89: 125-136, 2015.

32. Jain V, Garg A, Parascandola M, Chaturvedi P, Khariwala SS and Stepanov I: Analysis of alkaloids in areca nut-containing products by liquid chromatography-tandem mass spectrometry. J Agric Food Chem 65: 1977-1983, 2017.

33. Merchant A, Husain SS, Hosain M, Fikree FF, Pitiphat W, Siddiqui AR, Hayder SJ, Haider SM, Ikram M, Chuang SK and Saeed SA: Paan without tobacco: An independent risk factor for oral cancer. Int J Cancer 86: 128-131, 2000.

34. World Health Organization: World Cancer Report 2003. Stewart BW and Kleihues P (eds). IARC Press, Lyon, 2003.

35. Adel M, Liao CT, Lee LY, Hsueh C, Lin CY, Fan KH, Wang HM $\mathrm{Ng} \mathrm{SH}$, Lin CH, Tsao CK, et al: Incidence and outcomes of patients with oral cavity squamous cell carcinoma and fourth primary tumors: A long-term follow-up study in a betel quid chewing endemic area. Medicine (Baltimore) 95: e2950, 2016.

36. Edge SB and Compton CC: The American Joint Committee on Cancer: The 7th edition of the AJCC cancer staging manual and the future of TNM. Ann Surg Oncol 17: 1471-1474, 2010.

37. McCarter K, Martínez Ú, Britton B, Baker A, Bonevski B, Carter G, Beck A, Wratten C, Guillaumier A, Halpin SA and Wolfenden L: Smoking cessation care among patients with head and neck cancer: A systematic review. BMJ Open 6: e012296, 2016.

38. Dresler CM, León ME, Straif K, Baan R and Secretan B: Reversal of risk upon quitting smoking. Lancet 368: 348-349, 2006.

39. Marron M, Boffetta P, Zhang ZF, Zaridze D, Wunsch-Filho V, Winn DM, Wei Q, Talamini R, Szeszenia-Dabrowska N, Sturgis EM, et al: Cessation of alcohol drinking, tobacco smoking and the reversal of head and neck cancer risk. Int J Epidemiol 39: 182-196, 2010.

40. Wax MK, Myers LL, Gabalski EC, Husain S, Gona JM and Nabi H: Positron emission tomography in the evaluation of synchronous lung lesions in patients with untreated head and neck cancer. Arch Otolaryngol Head Neck Surg 128: 703-707, 2002.

41. Glynn F, Brennan S and O'Leary G: CT staging and surveillance of the thorax in patients with newly diagnosed and recurrent squamous cell carcinoma of the head and neck: Is it necessary? Eur Arch Otorhinolaryngol 263: 943-945, 2006.
42. Eichler M, Keszte J, Meyer A, Danker H, Guntinas-Lichius O, Oeken J, Pabst F and Singer S: Tobacco and alcohol consumption after total laryngectomy and survival: A German multicenter prospective cohort study. Head Neck 38: 1324-1329, 2016.

43. Dequanter D, Shahla M, Lardinois I, Gilbert O, Hanquet O, Tragas G, Van Meerhæghe A and Lothaire P: Second primary lung malignancy in head and neck cancer patients. Eur Ann Otorhinolaryngol Head Neck Dis 128: 11-13, 2011.

44. León X, Martínez V, López M, García J, Venegas Mdel P, Esteller E and Quer M: Second, third, and fourth head and neck tumors. A progressive decrease in survival. Head Neck 34: 1716-1719, 2012.

45. León X, Martínez V, López M, Lorenzo JG and Quer M: Risk of third and fourth tumors in patients with head and neck cancer. Head Neck 32: 1467-1472, 2010.

46. Li D, Yegya-Raman N, Kim S, Ganesan S, Sayan M, August D, Spencer K, Hathout L, Maloney-Patel N, Malhotra U, et al: Multiple primary malignancies in patients with anal squamous cell carcinoma. J Gastrointest Oncol 9: 853-857, 2018.

47. Götz C, Bischof C, Wolff KD and Kolk A: Detection of HPV infection in head and neck cancers: Promise and pitfalls in the last ten years: A meta-analysis. Mol Clin Oncol 10: 17-28, 2019.

48. Gao P, Gong L and Wang X: Induction chemotherapy in patients with resectable laryngeal cancer: A meta-analysis. Mol Clin Oncol 9: 155-162, 2018.

49. Al-Taei S, Banner R, Powell N, Evans M, Palaniappan N, Tabi Z and Man S: Decreased HPV-specific T cell responses and accumulation of immunosuppressive influences in oropharyngeal cancer patients following radical therapy. Cancer Immunol Immunother 62: 1821-1830, 2013.

50. Berrington de Gonzalez A, Curtis RE, Kry SF, Gilbert E, Lamart S, Berg CD, Stovall M and Ron E: Proportion of second cancers attributable to radiotherapy treatment in adults: A cohort study in the US SEER cancer registries. Lancet Oncol 12: 353-360, 2011.

51. Morales-Sánchez A and Fuentes-Pananá EM: Human viruses and cancer. Viruses 6: 4047-4079, 2014.

This work is licensed under a Creative Commons Attribution-NonCommercial-NoDerivatives 4.0 International (CC BY-NC-ND 4.0) License. 